\title{
TREATMENT OF WASTEWATER CONTAINING PRINTING DYES: SUMMARY AND PERSPECTIVES
}

\author{
Đurđa Kerkez ${ }^{1}$ (D), Milena Bečelić-Tomin ${ }^{1}$ (D), Gordana Pucar Milidrag ${ }^{1}$ (D), Vesna Gvoić ${ }^{2}$ (D), \\ Aleksandra Kulić Mandić ${ }^{1}$ (D), Anita Leovac Maćerak ${ }^{1}$ (D), Dragana Tomašević Pilipović ${ }^{1}$ (D) \\ ${ }^{1}$ University of Novi Sad, Faculty of Sciences, Department of Chemistry, Biochemistry and \\ Environmental Protection, Novi Sad, Serbia \\ ${ }^{2}$ University of Novi Sad, Faculty of Technical Sciences, Department of Graphic Engineering and \\ Design, Novi Sad, Serbia
}

\begin{abstract}
Synthetic dyes are widely used in textile, printing, leather tanning, cosmetic, drug and food processing industries. The printing and dyeing industry is considered as one of the most polluting industrial sectors. The printing process is very versatile and includes printing on paper as well as printing on textile, plastic and other materials. After the printing process is completed, various chemicals such as ethers, alcohols, phenols, aldehydes, ketones, benzene, and esters are used in the cleaning procedure. Resulting wastewater often contains a variety of solvents, surfactants, dyes, and other chemicals, thus greatly increasing the difficulty of wastewater treatment. Improper discharge of printing and dyeing wastewater into water bodies will have several effect, beginning with aesthetical issues followed by destruction of the aqueous ecosystem due to light attenuation, oxygen consumption and toxicity effects. Therefore, it is very important to find out and optimize printing and dying wastewater treatment techniques. Processes for dye removal from wastewater can be physical, chemical, biological and more recently hybrid treatments. Physical processes such as adsorption, based on mass transfer mechanism, are commonly used method mainly due to ease of operation and high efficiency. Chemical processes including coagulation and flocculation, advanced oxidation processes and electrochemical treatment are usually more expensive due t chemicals use, equipment requirements and electrical energy consumption. However, these techniques are destructive and may lead to total mineralization of dye molecules and accompanying pollutants. Biological treatment is a low-cost and environmentally friendly process that produces less sludge. This method has significant advantages but dye molecules are less prone to this kind of treatment as they are made to be stable and reluctant. So, the adjustment and optimization of biological treatment, for dye removal, is an ongoing field of research. In recent studies hybrid processes are gaining more attention, combining different techniques. Integrating treatments, as a cost-saving and time-saving process, can represent optimal solution for printing wastewater treatment.
\end{abstract}

Key words: printing dyes, wastewater management, wastewater treatment, decolourization, mineralization

\section{INTRODUCTION}

Fast industrial development and overpopulation have caused serious contamination of the freshwater resources with different kind of pollutants.. These organic and inorganic contaminants pose serious health risks to humans and wildlife. Among these pollutants, dyes and pigments, as a large group of pollutants, are of major concern. These substances are utilized in industries such as textile, plastic, leather, paint, cosmetics, printing, and paper (Shah, 2018; Wazir, 2020). Around 10000 types of synthetic and natural dyes are produced every year all over the world which is roughly weighed in between $7 \times 10^{5}-$ $1 \times 10^{6}$ tons and a significant amount of dyes is wasted during manufacturing and application processes . Large amount of chemicals and dyestuffs are remaining unused during textile dying and printing process and is discharged as excess waste effluent into the environment (Chowdhury et al, 2020; Katheresan et al, 2018). Synthetic dyes and pigments released into the environment in the form of industrial effluents causes severe ecological problems. This kind of wastewater is intensively coloured with varying degrees of chemical oxygen demand. Neither simple chemical nor biological treatment alone has proved adequate in decolourization and sufficient depletion of organic matter (Swaminathan et al, 2005). Generally, printing and dyeing wastewaters are characterized by high $\mathrm{pH}$ value, low ratio of $\mathrm{BOD}_{5} / \mathrm{COD}$, toxic and contain bio-recalcitrant compounds. Chemicals such as sulphur, naphthols, dyes, aromatic amines, acetic acid, soaps, chromium compounds and heavy metals are identified in this wastewaters making them highly toxic. As a result, treatment of this king of effluents is challenging from 
engineering aspect. Various approaches such as aerobic, anaerobic and anaerobic combined with oxic biological treatments have been reported in wastewater treatment. Due to the inhibitory nature of many compounds in these effluents for biological oxidation, pretreatment is often required and chemical oxidation as well as adsorption and membrane technology are highlighted in treating and separating complex organic compounds (Zhang et al, 2012; Zhu et al, 2018).

\section{BIOLOGICAL AND PHYSICAL-CHEMICAL PROCESESS}

Regarding biological process, activated sludge plays an essential role in decolourization and degradation of dyes to inorganic products. Treatment efficiency of activated sludge depends on the characteristics of the microorganisms involved in biological community. Specialized cultures are necessary for decolourization of dyes. In recent years, with the development of molecular biological techniques, highthroughput sequencing technology, which overcomes the limitation of conventional techniques, is developed, become the most popular method for the evaluation of microbial community. Contaminants and microorganisms involved in the printing and dying wastewater biotransformation process are complicated. Finding the important functional bacteria is difficult if activated sludge is studied directly for this kind of wastewater. Decolourization of, for example, azo dyes was firstly happened by the cleavage of $\mathrm{N}-\mathrm{N}$ bond, producing aromatic amines. Further on, to aromatic rings were remained after hydrolyzation of, resulting in the formation of phenol and naphthol. Then ring opening reactions occurred by introducing the atoms of $\mathrm{O}_{2}$ into the aromatic nucleus. Further mineralization goes towards end products into $\mathrm{CO}_{2}$ and $\mathrm{H}_{2} \mathrm{O}$. For azo dyes genera of Enterococcus, Acidaminococcus, Bacteroides, Megasphaera, Klebsiella demonstrated significantly positive relationships with cleavage of $\mathrm{N}-\mathrm{N}$, while Pseudomonas, Anaerovorax and Longilinea played important roles in breaking the aromatic rings (Zhu et al, 2018).

Reverse osmosis process, are one of physical processes, that has been widely applied in printing and dyeing wastewater treatment as it can effectively barrier various organic/inorganic contaminants and also biological constituents. After being treated, a large proportion of influent stream can be reused directly in printing and dyeing process, while the residual reverse osmosis concentrate (ROC) of printing and dyeing wastewater, which is characterized by recalcitrant organics, high hardness and high salinity, cannot be directly discharged and still remains serious environmental risks. On the other hand, the physical and chemical treatments such as coagulation, membrane distillation and adsorption will eventually cause secondary pollution and most of them come with a high waste disposal cost (Wang et al, 2018).

The adsorption process is one of the potential and efficient methods among all the possible techniques for coloured effluent treatment due to its low initial investment, design simplicity and availability of lowcost adsorbents. Low-cost and readily available natural bio-adsorbents are commonly applied for the elimination of several kinds of pollutants from printing and dying wastewater. They have developed specific surface area and functional properties. Bio-sorbents are considered possible substitute for the costly and currently existing activated carbon for the uptake of the dyes from aqueous media. Removal capacity can reach $40.89 \%$ to $69.76 \%$ with the decrease of initial concentration (Chowdhury et al, 2020).

Electrocatalytic technology has also been used for the treatment of pollutants that are more toxic and difficult to handle. There are several advantages of the electrocatalytic technology, such as simple equipment, easy operation, high removal efficiency, and little sludge generation. Among many kinds of electrocatalytic materials, titanium dioxide $\left(\mathrm{TiO}_{2}\right)$ is relatively cheap. Our research team has applied $\mathrm{TiO}_{2}$ electrode to treat two types. With nano- $\mathrm{TiO}_{2}$ electrode, dye and $\mathrm{TOC}$ removal efficiencies can reach $97 \%$ and $56 \%$ after 160 -min treatment, respectively. Under the same operation conditions but using two pairs of electrodes, the removal efficiencies of TOC and dye were enhanced to $75.0 \%$ and $82.0 \%$, respectively, and could be further improved to $90.0 \%$ and $92 \%$ if the electrolytic effluent was polished by powder activated carbon absorption (Tung et al, 2013). Development of alternate methods that can degrade toxic organic compounds brought up ozone $\left(\mathrm{O}_{3}\right)$ that becoming a versatile and environmentally sound oxidation agent. Ozonation of water is a well-known technology and the strong oxidative properties of $\mathrm{O}_{3}$ have the ability to effectively oxidize many organic compounds. Due to its high electrochemical potential $(2.08 \mathrm{~V}), \mathrm{O}_{3}$ is the strongest oxidant available and applicable as compared to $\mathrm{H}_{2} \mathrm{O}_{2}(1.78 \mathrm{~V})$ and can react with several classes of compounds through direct or indirect reaction. $\mathrm{O}_{3}$ leaves no toxic residues that have to be removed or disposed. Ozone combinations are the most applied advanced oxidation processes (AOP) enhancing the biodegradability of wastewater. Maximum dye and COD (87.8\%) removal could be achieved at an ozone dose of $4.33 \mathrm{mg} / \mathrm{I}$ at 30 min ozonation. In addition, Increase in the BOD $/$ COD ratio is observed after ozonation indicating that during ozonation biodegradability of reluctant printing and 
dying wastewater has increased. Besides ozonation, Fenton process is well known among AOPS that can reach almost $100 \%$ of dye removal (Swaminathan et al, 2005).

\section{PHOTOCHEMICAL PROCESSES}

Printing dyes wastewater contains significant amount of dye, therefore, the energy of light may be absorbed by organic molecule. As a result, the light penetration is limited to a thin layer. In order to prevent this many techniques, which use natural or artificial radiation, are widely used in treatment processes in order to provide cleaner water, some of them are described in this review.

\subsection{UV/ $\mathrm{H}_{2} \mathrm{O}_{2}$ process}

During the last decade, some researchers have reported the successful applications of the $U V / \mathrm{H}_{2} \mathrm{O}_{2}$ process of coloured wastewater treatment. Namely, when using hydrogen peroxide as oxidating agens under UV radiation, hydrogen peroxide is directly photolyzed in to two hydroxyl radicals (Rosa et al, 2020). During this process, ultraviolet radiation is used to cleave the O-O bond in molekul of hydrogen peroxide. Process of its photolysis is described by following reactions:

$$
\begin{aligned}
& \mathrm{H}_{2} \mathrm{O}_{2}+\mathrm{hv} \rightarrow 2 \mathrm{HO} \cdot \\
& \mathrm{H}_{2} \mathrm{O}_{2}+\mathrm{HO}^{\circ} \rightarrow \mathrm{HO}_{2}^{-}+\mathrm{H}_{2} \mathrm{O} \\
& \mathrm{H}_{2} \mathrm{O}_{2}+\mathrm{HO}_{2}^{-} \rightarrow \mathrm{HO} \cdot+\mathrm{H}_{2} \mathrm{O}+\mathrm{O}_{2} \\
& 2 \mathrm{HO} \rightarrow \mathrm{H}_{2} \mathrm{O}_{2} \\
& 2 \mathrm{HO}_{2}^{-} \rightarrow \mathrm{H}_{2} \mathrm{O}_{2}+\mathrm{O}_{2} \\
& \mathrm{HO}^{-}+\mathrm{HO}_{2}^{-} \rightarrow \mathrm{H}_{2} \mathrm{O}+\mathrm{O}_{2}
\end{aligned}
$$

Reaction 1 is rate limiting when compared with other reactions that have much higher rate. Also, higher initial dose of hydrogen peroxide provide more generated hydroxil radicals, but too much peroxide will lead to reaction with hydroxyl radical and formation of $\mathrm{HO}_{2} \bullet$ (reaction 2). The major factors affecting this process are the initial concentration of the target compound, the amount of $\mathrm{H}_{2} \mathrm{O}_{2}$ used (beyond its optimum limit the presence of $\mathrm{H}_{2} \mathrm{O}_{2}$ in excess will lead to scavenging action). Wastewater $\mathrm{pH}$ ( $\mathrm{pH}$ values 2.5 - 3.5 are mostly used, but it really depends on the pKa of the target compounds), presence of bicarbonate (the increase of bicarbonate anion concentration affected negatively its removal) and reaction time. Process degradation kinetic rate is inversely proportional to the initial concentration of the pollutant (Stasinakis, 2008).

\subsection{Photocatalytic degradation}

Photocatalysis is the process in which photoactivation of semiconductors is initiated by irradiation, with electron-hole pairs appearing as a result of band gap excitation. Positive holes generated by light can react with electron donors and generate hydroxile radicals (Alinsafi et al, 2007). Organic compounds which include dyes, can undergo oxidative degradation through their reactions with valence bond holes, hydroxyl and peroxide radicals as well as reductive cleavage through their reactions with electrons. The most widely used metal oxide semiconductor is $\mathrm{TiO}_{2}$ because of its photocatalytic and strong metal support interaction properties as well as, possibility of operating at ambient conditions, the lack of mass transfer limitations when nanoparticles are used as photocatalysts and the possible use of solar irradiation. Moreover, $\mathrm{TiO}_{2}$ is a cheap, readily available material and the photogenerated holes are highly oxidizing (Sajan et al, 2010), Ag (Kavitha et al, 2014), ZrO2 (Suresh et al, 2015), NiO (Suresh et al, 2015) and $\mathrm{MgO}$ (Jorfi et al, 2016). In parallel, suspended composites begun to be used: $\mathrm{TiO}_{2} \mathrm{impregnated}_{\text {with }}$ 5 wt\% $\mathrm{Nb}_{2} \mathrm{O}_{5}$, magnetic ferrites $\left[\mathrm{CoFe}_{2} \mathrm{O}_{4}\right.$ ] encapsulated by $\mathrm{TiO}_{2}$ (Aquino, 2010), $\mathrm{TiO}_{2}$ supported molybdenum oxide catalyst (Sajan et al, 2010), $\mathrm{Ag}^{+}$doped $\mathrm{TiO}_{2}$ (Sahoo et al, 2012), $\mathrm{ZnO90 \% /Ag10 \%}$ (Saravanan et al, 2013), $\mathrm{TiO}_{2} / \mathrm{ZrO}_{2}$ (Das and Basu, 2015), $\mathrm{TiO}_{2} / \mathrm{SnO}_{2}$ (Karthikeyan et al, 2015), $\mathrm{ZnO} / 15 \mathrm{Zn}_{2} \mathrm{SnO}_{4}$ (Danwittayakul et al, 2015), cerium doping $\mathrm{TiO}_{2}$ (Touati et al, 2016), CulnSe (Karthikeyan et al, 2017). Recently, composites/nanocomposites have been increasingly used such as: copper 
sulfide/reduced graphene oxide (Saranya et al, 2015), ZnO/CdO (Saravanan et al, 2015), ZnO/Ag/CdO (Saravanan et al, 2015) and iodine doped $\mathrm{TiO}_{2}$ (Barkul, 2017). Also, in the synthesis of the catalyst, it is important to take into account its easy separation from wastewater due to their particle sizes sizes (for example calcinated semiconductors) (Souza et al, 2017). Moreover, materials with good adsorption have been added to photocatalysts - powdered active carbon (Dhas et al, 2015), Lewatit anion exchange resin (Dhas et al, 2015), scoria coated with $\mathrm{ZnO}$ (Mahdizadeh et al, 2015), ZrO2, NiO and $\mathrm{ZnO}$ loaded activated carbon (Suresh et al, 2015) and zeolite coated with $\mathrm{TiO}_{2}$ (Guesh et al, 2016).

\subsection{Photo-Fenton process}

The photo-Fenton (or photo-assisted Fenton) process involves the use of solar radiation or an artificial radiation source, which increases the rate of contaminant degradation by stimulating the reduction of ferric ions $\left(\mathrm{Fe}^{3+}\right)$ to ferric ions $\left(\mathrm{Fe}^{2+}\right)$ (Parsons, 2005). This process shows high efficiency of oxidation of organic pollutants and inactivation of microorganisms in wastewater (Villegas-Guzman et al, 2017). The photo-Fenton process is a combination of iron ions, hydrogen peroxide and solar and UV-VIS radiation ( $\lambda$ $<600 \mathrm{~nm}$ ), which leads to higher production of hydroxyl radicals through the following reactions: 1$)$ reduction of $\mathrm{Fe}^{3+}$ to $\mathrm{Fe}^{2+}(7)$ and 2) photolysis of hydrogen peroxide at smaller wavelengths (8) (Pouran et al, 2015).

$$
\begin{aligned}
& \mathrm{Fe}(\mathrm{OH})^{2+}+\mathrm{hv} \rightarrow \mathrm{Fe}^{2+}+\mathrm{HO}^{-} \\
& \mathrm{H}_{2} \mathrm{O}_{2}+\mathrm{hv} \rightarrow 2 \mathrm{HO}^{-}
\end{aligned}
$$

The ferro ions formed by the photo-Fenton reaction will further react with hydrogen peroxide [Fenton reaction] generating additional hydroxyl radicals, which will increase the rate of oxidation of the photoFenton process, reduce iron consumption and sludge formation compared to the Fenton process (Pouran et al, 2015).

In addition, research has shown that the use of iron species [ions, iron mixed with other species or other complexes on a solid] support can: prevent sludge formation, overcome iron release into the effluent, and overcome the challenge of range of operational $\mathrm{pH}$ and the challenge of iron removal from sludge before discharge. However, modified clays, used as catalysts, such as (Yatmaz and Sen, 2018) zeolite (Bokare and Choi, 2014) silica fabric (Moncayo-Lasso et al, 2008) resins (De Oliveira et al, 2007) and Alumina (Clarizia et al, 2017) showed good results in treatment of dye removal. Moreover, a chelate can be considered suitable for photo-Fenton process. Common iron-chelating agents are: citric acid, oxalic acid, Ethylenediamine Tetra Acetic Acid (EDTA), Ethylenediamine- $N, N^{\prime}$-disuccinic acid (EDDS), Nitrilotriacetic acid (NTA). They can provide neutral conditions of the reaction and it is very important that they are benign, resistant to oxidation in the medium of application and is able to generate $\mathrm{HO} \bullet$ or other reactive oxidants. It should also possess high iron-chelate complexation strength. As photo-Fenton showed good results in dye removal, scientists investigated also non ferous catalyst such as are cerium, copper, manganese, wich has to have multiple oxidation states to be adequate replacement for iron in order to generate hydroxyl radicals from $\mathrm{H}_{2} \mathrm{O}_{2}$ at wide $\mathrm{pH}$ ranges, making the process appropriate for the treatment of various dyes (Alinsafi et al, 2007).

\section{CONCLUSIONS}

No technique fully capable of satisfactory treatment exists since the nature of effluents from dying and printing industries contains complex compounds. Various processes different in nature were applied in research for treating this kind of effluents. High efficiencies od effluent decolourization is achieved, but main problem that remains is mineralization degree of remaining effluents. Many scientific researches are focused on biological treatments, while some of them had attended to chemical or physical treatments. For further improvement, a combination of several treatments known as hybrid processes is becoming a practice to gain the most efficient quality in the most economical way. 


\section{ACKNOWLEDGMENTS}

Author acknowledge the Science Fund of the Republic of Serbia for the Program for excellent projects of young researchers (PROMIS) - WasteWaterForce project (6066881). Additionally, this research has been supported by the Ministry of Education, Science and Technological Development through the projects No. 451-03-68/2020-14/200156: "Innovative scientific and artistic research from the FTS (activity) domain".

\section{REFERENCES}

[1] Alinsafi, A., Evenou, F. Abdulkarim, E.M.,Pons, M.N., Zahraa, O., Benhammou, A., Yaacoubi, A., Nejmeddine A.: "Treatment of textile industry wastewater by supported photocatalysis", Dyes Pigments 74, 439-445, 2007. doi: 10.1016/j.dyepig.2006.02.024.

[2] Aquino, S.F., Lacerda, C.A., Ribeiro, D.R.: "Use of ferrites encapsulated with titanium dioxide for photodegradation of azo dyes and color removal of textile effluents", Environmental Engineering Science 27(12), 1049-1059, 2010. doi: 10.1089/ees.2010.0249.

[3] Barkul, R.P., Patil, M.K., Patil, S.M., Shevale, V.B., Delekar, S.D.: "Sunlight-assisted photocatalytic degradation of textile effluent and Rhodamine B by using iodine doped TiO2 nanoparticles", Journal of Photochemistry and Photobiology A: Chemistry 349, 138-147, 2017. doi: 10.1016/j.jphotochem.2017.09.011.

[4] Bokare, A.D., Choi, W.: "Review of iron-free Fenton-like systems for activating H2O2 in advanced oxidation processes", Journal of Hazardous Materials 275, 121-135, 2014. doi: 10.1016/j.jhazmat.2014.04.054.

[5] Yatmaz, C.H., Sen U.D.K.: "Photocatalytic efficiencies of alternate heterogeneous catalysts: Iron modified minerals and semiconductors for removal of an AZO dye from solutions", Environment Protection Engineering 44(1), 2018. doi: 10.5277/epe180101.

[6] Chowdhury, M.F., Khandaker, S., Sarker, F., Islam, A., Rahman, M.T., Awual, R.: "Current treatment technologies and mechanisms for removal of indigo carmine dyes from wastewater: A review", Journal of Molecular Liquids 318, 2020. doi: 10.1016/j.molliq.2020.114061.

[7] Clarizia, L., Russo, D., Di Somma, I., Marotta, R. Andreozzi R.: "Homogeneous photo-Fenton processes at near neutral pH: A review“, Applied Catalysis B Environmental 209, 358-371, 2017. doi: 10.1016/j.apcatb.2017.03.011.

[8] Danwittayakul, S., Jaisai, M. Dutta, J.: "Efficient solar photocatalytic degradation of textile wastewater using ZnO/ZTO composites", Applied Catalysis B Environmental 163, 1-8, 2015. doi: 10.1016/j.apcatb.2014.07.042.

[9] Das, L., Basu, J.K.: "Photocatalytic treatment of textile effluent using titania-zirconia nano composite catalyst", Journal of Industrial and Engineering Chemistry 24, 245-250, 2015. doi: 10.1016/j.jiec.2014.09.037.

[10] De Oliveira, I.S., Viana, L., Verona, C., Fallavena, V.L.V., Azevedo, C.M.N., Pires M.: “Alkydic resin wastewaters treatment by fenton and photo-Fenton processes", Journal of Hazardous Materials 146(3), 564-568, 2007. doi: 10.1016/j.jhazmat.2007.04.057.

[11] Dhas, P.G.T.N., Gulyas,H., Otterpohl, R.: "Impact of powdered activated carbon and anion exchange resin on photocatalytic treatment of textile wastewater", Journal of Environmental Protection 6(3), 191-203, 2015. doi: 10.4236/jep.2015.63020.

[12] Guesh, K., Mayoral, Á., Márquez-Álvarez, C., Chebude, Y., Díaz I.: "Enhanced photocatalytic activity of TiO2 supported on zeolites tested in real wastewaters from the textile industry of Ethiopia", Microporous and Mesoporous Materials 225, 88-97, 2016. doi: 10.1016/j.micromeso.2015.12.001.

[13] Jorfi, S., Barzegar, G., Ahmadi, M., Darvishi Cheshmeh Soltani, R., Alah Jafarzadeh Haghighifard, N., Takdastan, A., Saeedi, R., Abtahi, M.: "Enhanced coagulation-photocatalytic treatment of Acid red 73 dye and real textile wastewater using UVA/synthesized MgO nanoparticles", Journal of Environmental Management 177, 111-118, 2016. doi: 10.1016/j.jenvman.2016.04.005.

[14] Karthikeyan, N., Narayanan, V., Stephen, A.: "Degradation of textile effluent using nanocomposite TiO2/SnO2 semiconductor Photocatalysts", International Journal of ChemTech Research 8(11), 443 449, 2015. 
[15] Karthikeyan, N., Sivaranjani, T., Dhanavel, S., Gupta, V.K., Narayanan, V., Stephen A.: “Visible light degradation of textile effluent by electrodeposited multiphase CulnSe2 semiconductor photocatalysts", Journal of Molecular Liquids 227, 194-201, 2017. doi: 10.1016/j.molliq.2016.12.019.

[16] Katheresan, V., Kansedo, J., Lau, S.Y.: "Efficiency of various recent wastewater dye removal methods: a review", Journal of Environmental Chemical Engineering 6(4), 4676-4697, 2018. doi: 10.1016/j.jece.2018.06.060.

[17] Kavitha, S.R., Umadevi, M., Janani, S.R., Balakrishnan, T. Ramanibai R.: "Fluorescence quenching and photocatalytic degradation of textile dyeing waste water by silver nanoparticles", Spectrochimica Acta Part A: Molecular and Biomolecular Spectroscopy 127, 115-121, 2014. doi: 10.1016/j.saa.2014.02.076.

[18] Mahdizadeh, F., Aber, S., Karimi A.: "Synthesis of nano zinc oxide on granular porous scoria: application for photocatalytic removal of pharmaceutical and textile pollutants from synthetic and real wastewaters", Journal of the Taiwan Institute of Chemical Engineers 49, 212-219, 2015. doi: 10.1016/j.jtice.2014.11.021.

[19] Moncayo-Lasso, A., Torres-Palma, R.A., Kiwi, J., Benítez, N., Pulgarin C.: "Bacterial inactivation and organic oxidation via immobilized photo-Fenton reagent on structured silica surfaces", Applied Catalysis B: Environmental 84(3-4), 2008. doi: 10.1016/j.apcatb.2008.05.022.

[20] Parsons, S.: "Advanced Oxidation Processes for Water and Wastewater Treatment", (IWA Publishing, 2005.).

[21] Pouran, S.M., Abdul Aziz, A.R., Ashri Wan Daud, W.M.: "Review on the main advances in photoFenton oxidation system for recalcitrant wastewaters", Journal of Industrial and Engineering Chemistry 21, 53-69, 2015. doi: 10.1016/j.jiec.2014.05.005.

[22] Rosa, J.M., Tambourgi, E.B, Vanalle, R.M., Gamarra, F.M.C., Santana, J.C.C., Araújo, M.C.: "Application of continuous H2O2/UV advanced oxidative process as an option to reduce the consumption of inputs, costs and environmental impacts of textile effluents", Journal of Cleaner Production 246, 2020. doi: 10.1016/j.jclepro.2019.119012.

[23] Sahoo, C., Gupta, A.K., Pillai, I.M.S.: "Heterogeneous photocatalysis of real textile wastewater: evaluation of reaction kinetics and characterization", Journal of Environmental Science and Health, Part A 47, 2109-2119, 2012. doi: 10.1080/10934529.2012.695996.

[24] Sajan, C.P., Shahmoradi, B., Shivaraju, H.P., Rai, K.M.L., Ananda, S., Shayan, M.B., Thonthai, T., Rao, G.V.N., Byrappa, K.: "Photocatalytic degradation of textile effluent using hydrothermally synthesised titania supported molybdenum oxide photocatalyst", Material Research Innovations 14, 2010. doi: 10.1179/143307510X12599329343484.

[25] Saranya, M., Ramachandran, R., Kollu, P., Jeong, S.K., Grace. A.N.: "A template-free facile approach for the synthesis of CuS-rGO nanocomposites towards enhanced photocatalytic reduction of organic contaminants and textile effluents“, RSC Advances 5, 15831-15840, 2015. doi: 10.1039/C4RA09029B.

[26] Saravanan, R., Gracia, F., Khan, M.M., Poornima, V., Gupta, V.K., Narayanan, V., Stephen. A.: "ZnO/CdO nanocomposites for textile effluent degradation and electrochemical detection", Journal of Molecular Liquids 209, 374-380, 2015. doi: 10.1016/j.molliq.2015.05.040. (a)

[27] Saravanan, R., Karthikeyan, N., Gupta, V.K., Thirumal, E., Thangadurai, P., Narayanan, V., Stephen, A.: "ZnO/Ag nanocomposite: an efficient catalyst for degradation studies of textile effluents under visible light", Materials Science and Engineering 33, 2235-2244, 2013.

[28] Saravanan, R., Mansoob Khan M., Gupta, V.K., Mosquera, E., Gracia, F., Narayanan, V., Stephen A.: " $\mathrm{ZnO} / \mathrm{Ag} / \mathrm{CdO}$ nanocomposite for visible light-induced photocatalytic degradation of industrial textile effluents",Journal of Colloid and Interface Science 452, 126-133, 2015. doi: 10.1016/j.jcis.2015.04.035 (b)

[29] Shah, M.P.: "Bioremediation-waste water treatment", Journal of Bioremediation and Biodegradation 9, 2018. doi: 10.4172/2155-6199.1000427.

[30] Souza, R.P., Ambrosio, E., Souza, M.T.F., Freitas, T.K.F.S., Ferrari-Lima, A.M., Garcia J.C.: "Solar photocatalytic degradation of textile effluent with $\mathrm{TiO} 2, \mathrm{ZnO}$, and $\mathrm{Nb} 2 \mathrm{O} 5$ catalysts: assessment of photocatalytic activity and mineralization“, Environmental Science and Pollution Research 24, 12691-12699, 2017. doi: 10.1007/s11356-017-8408-8.

[31] Stasinakis, A.S.: "Use of selected advanced oxidation processes (AOPs) for wastewater treatment - A mini review“, Global Nest Journal 10(3), 376-385, 2008. 
[32] Suresh, P., Vijaya, J.J., Kennedy, L.J.: "Photocatalytic degradation of textile dyeing wastewater through microwave synthesized Zr-AC, Ni-AC and Zn-AC", Transactions of Nonferrous Metals Society of China, 25 (12), 4216-4225, 2015. doi: 10.1016/S1003-6326(15)64072-9.

[33] Swaminathan, K., Pachhade, K., Sandhya, S.: "Decomposition of a dye intermediate, (H-acid] 1 amino-8-naphthol-3,6 disulfonic acid in aqueous solution by ozonation", Desalination 186, 155-164, 2005. doi: 10.1016/j.desal.2005.05.018

[34] Touati, A., Hammedi, T. Najjar, W., Ksibi, Z. Sayadi, S.: "Photocatalytic degradation of textile wastewater in presence of hydrogen peroxide: effect of cerium doping titania", Journal of Industrial and Engineering Chemistry 35, 36-44, 2016. doi: 10.1016/j.jiec.2015.12.008.

[35] Tung, C.H., Shen, S.Y., Chang, J.H., Hsu, Y.M., Lai, Y.C.: "Treatment of real printing wastewater with an electrocatalytic process", Separation and Purification Technology 117, 131-136, 2013. doi: 10.1016/j.seppur.2013.07.028.

[36] Villegas-Guzman, P., Giannakis, S., Torres-Palma, R.A., Pulgarin C.: "Remarkable enhancement of bacterial inactivation in wastewater through promotion of solar photo-Fenton at near-neutral pH by (natural organic acids", Applied Catalysis B: Environmental 205, 219-227, 2017. doi: 10.1016/j.apcatb.2016.12.021.

[37] Wang, J., Zhang, T., Mei, Y., Pan, B.: „Treatment of reverse-osmosis concentrate of printing and dyeing wastewater by electro-oxidation process with controlled oxidation-reduction potential (ORP)", Chemosphere 201, 621-626, 2018. doi: 10.1016/j.chemosphere.2018.03.051.

[38] Wazir, M.B., Daud M., Ali F., Al-Harthi M.A.: "Dendrimer assisted dye-removal: A critical review of adsorption and catalytic degradation for wastewater treatment", Journal of Molecular Liquids 315, 2020. doi: 10.1016/j.molliq.2020.113775.

[39] Zhang, J.X., Zhang, Y.B., Quan, X., Li, Y., Shuo, C., Zhao, H., Wang, D.: "An anaerobic reactor packed with a pair of Fe-graphite plate electrodes for bioaugmentation of azo dye wastewater treatment", Biochemical Engineering Journal 63, 31-37, 2012. doi: 10.1016/j.bej.2012.01.008.

[40] Zhu, Y., Xua, J., Cao, X., Cheng, Y.: "Characterization of functional microbial communities involved in different transformation stages in a full-scale printing and dyeing wastewater treatment plant", Biochemical Engineering Journal 137, 162-171, 2018. doi: 10.1016/j.bej.2018.05.026.

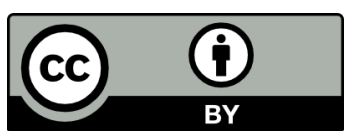

(C) 2020 Authors. Published by the University of Novi Sad, Faculty of Technical Sciences, Department of Graphic Engineering and Design. This article is an open access article distributed under the terms and conditions of the Creative Commons Attribution license 3.0 Serbia (http://creativecommons.org/licenses/by/3.0/rs/). 